\title{
Sismicidad en regiones del norte de Chile
}

\author{
Nelson Osvaldo Infante Fabres ${ }^{1}$
}

Recibido: 10 de abril de 2017 - Aceptado: 12 de mayo de 2017

\begin{abstract}
Resumen
El presente artículo trata acerca de la sismicidad y de los eventos sísmicos que afectaron durante el mes de marzo y abril del año 2014 a la zona norte de Chile, específicamente, a las regiones de Arica y Parinacota e Iquique y sus principales centros poblados, con un evento sísmico magnitud 8,2 Mw. Se utilizó información del Servicio Nacional de Sismología, del Servicio Hidrográfico y Oceanográfico de la Armada de Chile, para analizar tanto la actividad sísmica como sus efectos sobre algunas ciudades localizadas en el borde costero de las regiones norte, ante un potencial evento sísmico de magnitud superior a ocho grados Richter. Asimismo, en el texto se abordan algunos conceptos básicos de sismología que es necesario que la población conozca para comprender e internalizar que Chile es uno de los países que presenta una gran variedad de desastres naturales, especialmente sísmicos, a nivel mundial.
\end{abstract}

Palabras clave: Bordes de placas, cartas de inundación tsunámica, plano de Benioff, escala de magnitud del momento.

\section{Seismicity in Northern regions of Chile}

\begin{abstract}
This article addresses seismicity and seismic events affecting the North of Chile during March and April, 2014, specifically at Arica and Parinacota and Iquique regions and the main inhabited areas, with a seismic event of 8.2 Mw in magnitude. It uses information from the National Seismology Service and the Hydrographic and Oceanographic Service of the Chilean Navy to analyze both the seismic activity and the effects on some cities located on the coastal border of the Northern regions, in the potential case of a seismic event stronger than 8 Richter grades in magnitude. The paper also addresses some basic concepts of seismology necessary for the population to understand
\end{abstract}

1 Chileno. Geógrafo, Universidad de Chile, Doctor en Geografía, Paisaje y Medio Ambiente, Universidad de Barcelona. Profesor adjunto, Departamento de Geografía, Universidad Alberto Hurtado, Chile. E-mail: ninfante@uahurtado.cl 
and internalize that Chile is one of the countries in the world presenting the major variety of natural disasters, especially of seismic nature.

Keywords: Plate edges, Tsunamis flood charts, Benioff plane, scale of magnitude at the moment.

\section{A atividade sísmica em regiões do norte do Chile}

\section{Resumo}

0 presente artigo é sobre a sismicidade e dos eventos sísmicos que afetaram durante o mês de março e abril do ano 2014 para o norte de Chile, especificamente, para as regiões de Arica e Parinacota e Iquique e seus principais centros populacionais, com um evento sísmico de magnitude $8.2 \mathrm{Mw}$. Utilizou-se informação do Serviço Nacional de Sismologia, do Serviço Hidrográfico e Oceanográfico da Marinha do Chile para analisar tanto a atividade sísmica como também seus efeitos sobre algumas cidades localizadas no borde costeiro das áreas do Norte, ante um potencial evento sísmico de magnitude superior a oito graus Richter. Também no texto abordam-se alguns conceitos básicos de sismologia que é necessário que a população conheça para compreender e interiorizar que o Chile é um dos países que apresentam uma grande variedade de desastres naturais, especialmente sísmicos, a nível mundial.

Palavras-chave: Bordes de placas, cartas de inundação de Tsunami, plano de Benioff, escala de magnitude do momento.

Chile es uno de los países que constantemente sufre permanentes desastres naturales, como es el caso de inundaciones, erupciones volcánicas, terremotos, tsunamis, deslizamientos de laderas, remoción en masa, avalanchas, aluviones, caída de bloques, incendios forestales, entre otros, como resultado de su configuración estructural, localización geográfica y los patrones de asentamiento que ha adoptado la población a lo largo de su historia.

El terremoto del día 1 de abril de 2014 y sus incontables réplicas pusieron nuevamente en contingencia el tema de los riesgos sísmicos para la población en Chile. Si bien este terremoto fue de gran magnitud 8,2 Mw (magnitud del momento), no ocasionó un tsunami devastador como en un momento se pensó; por el contrario, en todas las costas del territorio nacional las variaciones del nivel del mar sólo alcanzaron valores máximos de 2,5 metros en lquique, altura de los trenes de olas (masas de agua), las que movieron embarcaciones menores, destruyéndolas y desplazándolas hasta cien metros tierra adentro, causando importantes pérdidas económicas a sus propietarios.

Por otra parte, el sismo causó daños de gravedad en variada infraestructura tanto domiciliaria como comercial; en la ciudad de lquique se observaron viviendas con serios daños estructurales, las cuales debieron ser evacuadas y 
abandonadas por sus moradores. En la ruta que une a lquique con la ciudad de Alto Hospicio se sucedieron deslizamientos de laderas que bloquearon la carretera en ambos sentidos e inclusive atraparon vehículos que, supuestamente, se encontraban en una zona de seguridad.

En la ciudad de Arica los daños se apreciaron en variadas estructuras, viviendas antiguas con caídas de muros, otras destruidas y algunos locales comerciales sufrieron daños en sus fachadas, pero no así estructurales. Lo que permite apreciar la magnitud del evento es la variedad de deslizamientos en torno al Morro de Arica, el cual perdió parte de su material, que bloqueó calles que se encuentran en su parte baja.

En la ciudad de Alto Hospicio, uno de los centros poblados con mayor daño en la zona cercana al epicentro, se registraron daños a estructuras comerciales, industriales, pero mayormente habitacionales, generando gran número de damnificados. A pesar de su localización, sobre el farellón costero y a una altitud de 600 metros aproximadamente, lo cual le deja fuera de cualquier riesgo tsunámico, esta entidad de población es muy dependiente por accesibilidad, conectividad con la ciudad de lquique; si se bloquea por deslizamientos la carretera que une a ambas urbes (Ruta 16, que posteriormente pasa a llamarse Alejandro Soria), la ciudad de Alto Hospicio queda desconectada de su principal centro de abastecimiento tanto económico, laboral, educacional y de salud.

El 16 de marzo del 2014 a las 18:16 horas (UTC 21:16 horas) coordenadas $19,965^{\circ}$ sur y una longitud de $70,814^{\circ}$ oeste a una profundidad superficial de $20,6 \mathrm{~km}$, el norte chileno se vio afectado por un sismo de mediana magnitud (6.5-6.7 Richter) que generó pánico en la población, que fue acompañado de una alerta de evacuación por un eventual tsunami, decretada por las autoridades pertinentes. Desde ese día comienza una seguidilla de sismos en dicha área de nuestro país.

El $1^{\circ}$ de abril a las 20.46 horas a $85 \mathrm{~km}$, al SW de la ciudad de lquique, a una profundidad de $44 \mathrm{~km}$, aproximadamente, se generó un violento sismo de $7.9^{\circ}$ a $8^{\circ}$ Richter, según la USGS de los Estados Unidos de América, el Servicio Sismológico de Chile corrige a $8.3^{\circ}$ de la escala Magnitud del Momento, generando una alerta tsunámica por el Servicio Hidrográfico y Oceanográfico de la Armada de Chile (SHOA) para todo el borde costero del país.

Técnicamente, para que se genere un tsunami deben darse varias características entre las que destacan, que el hipocentro o foco del sismo se genere en el mar, cercano a la costa, de poca profundidad, menos de $50 \mathrm{~km}$, y su magnitud sea igual o superior a $7.5^{\circ}$ escala Richter.

A esa fecha en el año, se habían registrado entre el sur del Perú y la Península de Mejillones más de mil sismos de variadas magnitudes y en la 
semana del $1^{\circ}$ al 7 de abril unos seiscientos aproximadamente, lo que induce a la especulación sobre un gran terremoto; es más, sólo en la última semana el Servicio Nacional de Sismología de la Universidad de Chile había registrado 283 sismos aproximadamente, de los cuales diez son de magnitud sobre los $4,5^{\circ} \mathrm{R}$., y cuyos focos o hipocentros se encuentran en las cercanías de la ciudad de Iquique; siete de ellos han registrado la misma magnitud, localizándose cercanos a la localidad de Cuya, varios kilómetros hacia el interior de la costa, cifra que en conjunto representa aproximadamente el seis por ciento de los sismos registrados en la última semana, razón suficiente para mantener en alerta a la población de la zona.

Si se visualiza la actividad sísmica para el mes de marzo de los últimos tres años, es posible contemplar cómo esta actividad ha aumentado en la zona de subducción marina, apreciándose en el año 2012 unos cuantos sismos de menor intensidad en el mar. El año 2013 estos son menores, concentrándose la mayoría de la actividad en la zona cordillerana, específicamente hacia la localidad de Pica; sin embargo, el año 2014 en el mes de marzo aflora una actividad permanente en el mar, con sismos de variadas magnitudes en la zona comprendida entre lquique y Cuya, concentrados a los $71^{\circ}$ de longitud Oeste, en el mar, próximos a la zona de contacto entre las placas de Nazca y Sudamericana (zona de subducción), manteniendo la actividad en la zona cordillerana más cercana a la ciudad de Ollagüe.

Figura 1 Mapas de sismicidad de los años 2012, 2013 y 2014

Año 2012

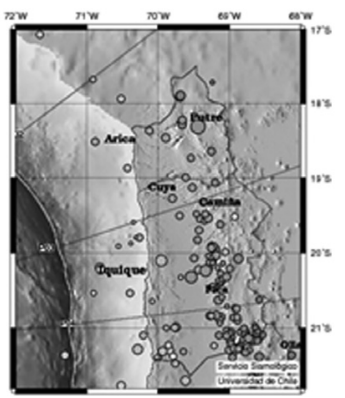

Año 2013

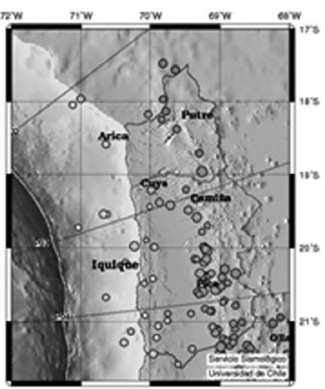

Año 2014

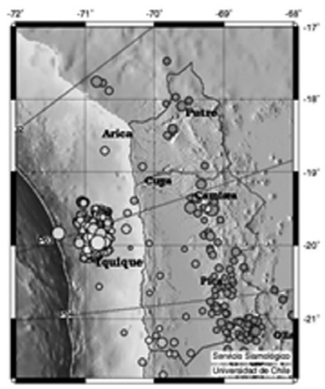

Fuente: Servicio de Sismología de la Universidad de Chile

Otro análisis complementario se puede llevar a cabo observando los perfiles sísmicos generados por la misma institución para el periodo de marzo del año 2014. En las figuras 2 y 3 se aprecia un considerable evento sísmicos en el plano de Benioff. 
Figura 2 Perfiles sísmicos del área periodo marzo 2014
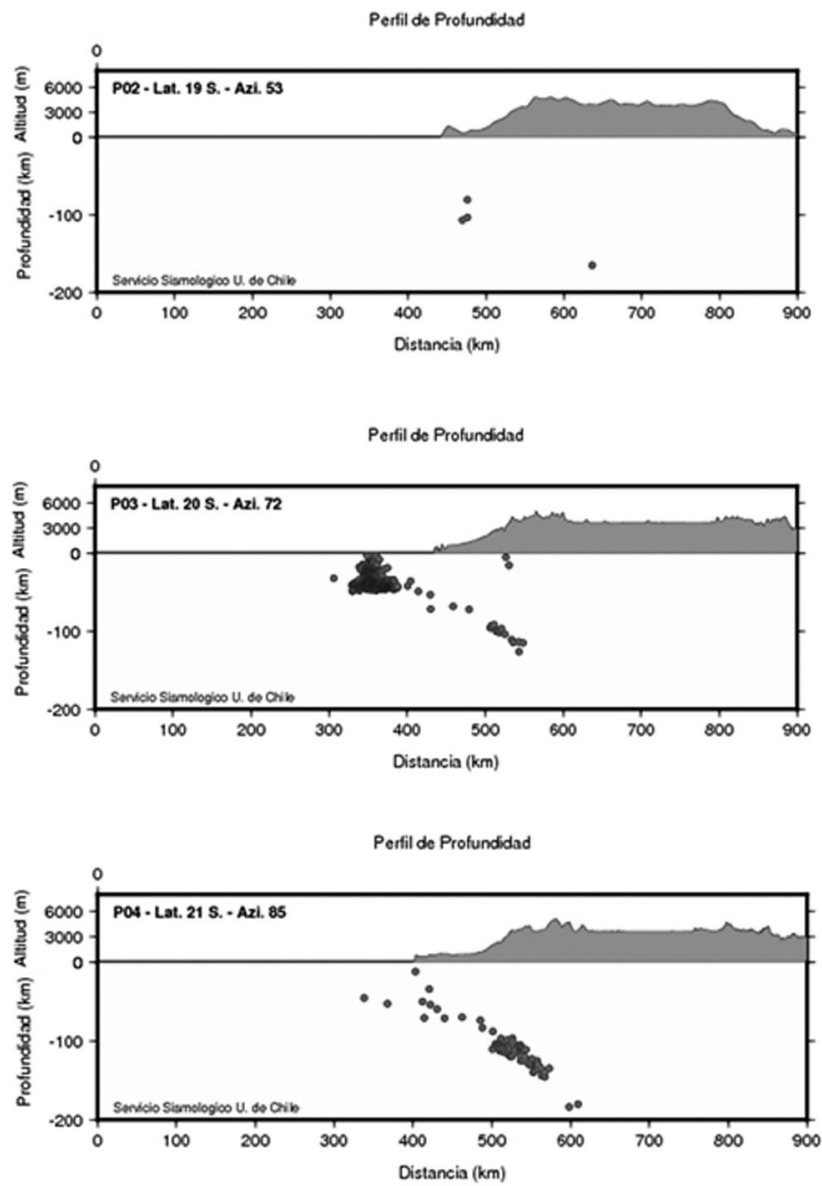

Fuente: Servicio Nacional de Sismología de la Universidad de Chile

En el primer perfil, desarrollado a los $19^{\circ}$ de latitud Sur y con un azimut de $53^{\circ}$, se observa que la actividad sísmica en esa dirección es menor, y se encuentra localizada entre los 80 y $180 \mathrm{~km}$. de profundidad hacia el interior del continente y dispersa en unos $200 \mathrm{~km}$. Por otra parte, en el segundo perfil confeccionado a los $20^{\circ}$ de latitud Sur y con un azimut de $72^{\circ}$, permite apreciar la aparición de una muy significativa actividad, dividida en dos sectores, la primera y más intensa aparece en la costa alcanzando 50 a 60 km. de profundidad desde la superficie, lo que da a entender que aunque sean eventos de menor magnitud, al ser superficiales pueden ser mejor percibidos por la población; además se enfocan en no más 60 a 70 km. de extensión sobre el fondo marino, es decir, muy cercanos a la zona de subducción, 
lo cual hace suponer que en estas zonas de contacto, se estaría liberando energía acumulada, aproximando los hipocentros entre sí. La segunda zona de actividad se encuentra a mayor profundidad, sobrepasando los $100 \mathrm{~km}$. y concentrándose en $50 \mathrm{~km}$. de extensión bajo el continente sudamericano.

El tercer perfil confeccionado a los $21^{\circ}$ de latitud Sur y con un azimut de $85^{\circ}$, permite observar que la actividad sísmica en esta dirección se encuentra principalmente bajo los $100 \mathrm{~km}$. de profundidad hacia el interior del continente y en no más de $80 \mathrm{~km}$. de extensión, dispersándose tanto en superficie como en profundidad hacia el océano.

Si observamos atentamente los tres perfiles, podemos distinguir claramente cómo la actividad sísmica se distribuye a lo largo de toda la zona de contacto entre las placas Sudamericana y Nazca, permitiendo identificar claramente lo que se denomina el Plano de Benioff.

La actividad sísmica en la primera semana de abril de 2014 se presenta en la Figura 3, a simple vista resulta obvio la inmensa actividad sísmica que se ha desarrollado, disparada por el terremoto del día 1 de abril, con una leve tendencia desde la localidad de Cuya hacia la ciudad de lquique, alcanzando hasta los $21^{\circ}$ de latitud Sur. Estos sismos inclusive se internan en el continente situándose bajo el farellón costero.

Figura 3 Mapa de sismicidad primera semana de abril de 2014

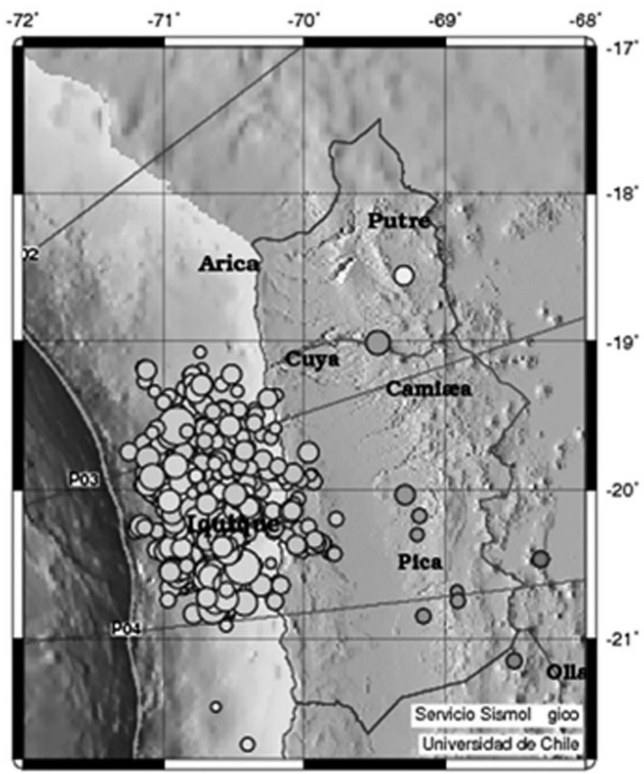

Fuente: Servicio Nacional de Sismología de la Universidad de Chile. 
Al analizar los perfiles sísmicos, se puede apreciar cómo la mayor cantidad de actividad sísmica se encuentra en los primeros $80 \mathrm{~km}$. de profundidad y en una extensión no mayor a $180 \mathrm{~km}$. de distancia (Perfil 1), localizados principalmente en la zona costera a los $20^{\circ}$ de latitud Sur aproximadamente.

En el segundo perfil elaborado a los $21^{\circ}$ de latitud, la actividad sísmica es aun más superficial, localizándose en los primeros $50 \mathrm{~km}$. de profundidad, en una extensión de territorio muy similar, próxima a los 150 km., con la diferencia de que en esta dirección también es posible observar otros sismos de mayor profundidad (sobre los 100 km.), bajo la Cordillera de la Costa.

Figura 4 Perfiles sísmicos del área primera semana de abril 2014
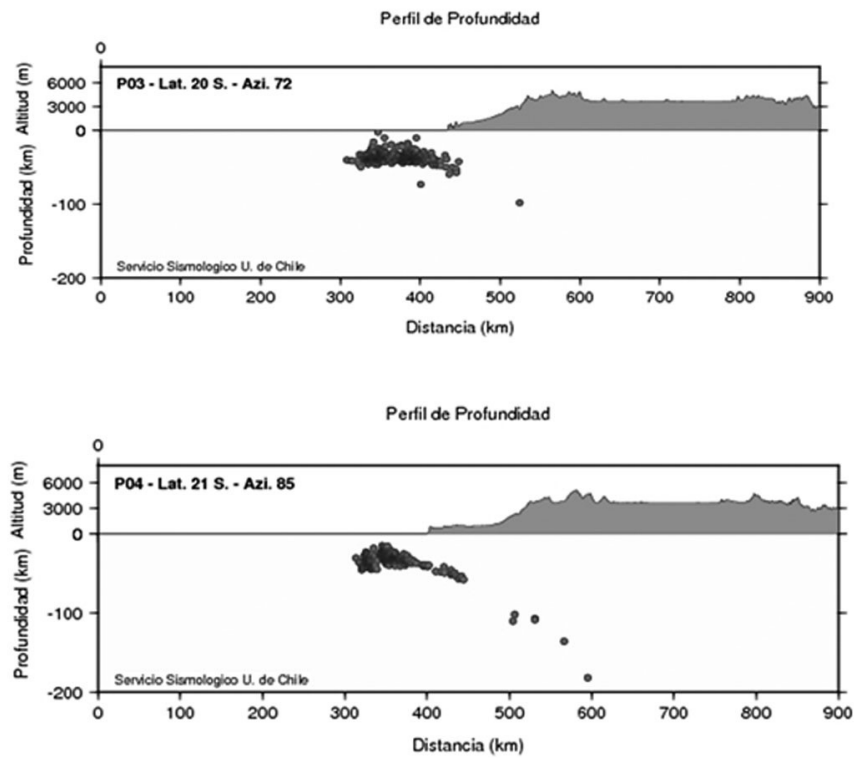

Fuente: Servicio Nacional de Sismología de la Universidad de Chile.

De acuerdo a la escala de magnitud del momento (Mw), que ha establecido que la energía liberada por sismos medianos y pequeños es mucho menor que la liberada por los grandes sismos, la equivalencia entre energías liberadas es muy diferente. Es así, por ejemplo, que se requiere de 33 millones de sismos Mw 3 o 31 mil sismos de Mw 5 para liberar la energía correspondiente a un evento sísmico de Mw 8 (Nava, 2011), por lo tanto se puede inferir que los sismos pequeños, en general, y en especial los que están afectando el norte chileno, no cumplen la función de válvula de escape para la energía acumulada que originaría sismos de mayor magnitud (mayores a Mw 8). 
Efectivamente hace ya un siglo y medio del terremoto que afectó a la ciudad de Arica, por lo tanto, se sabe que se ha acumulado energía, lo que hace inferir que dicha energía acumulada en algún momento se debe liberar; es lo que tiene tan inquietos a los habitantes del norte de nuestro país, pues se espera un sismo de mayor magnitud. Esto se debe a que la Placa de Nazca no ha subduccionado (hundido) adecuadamente bajo la Placa Sudamericana; este proceso de subducción se genera en la fosa Chileno-Peruana, también conocida como Fosa de Atacama, ubicada aproximadamente a unos 150 $\mathrm{km}$. al Oeste del continente americano.

Figura 5 Esquema de subducción de la placa Nazca bajo la Sudamericana

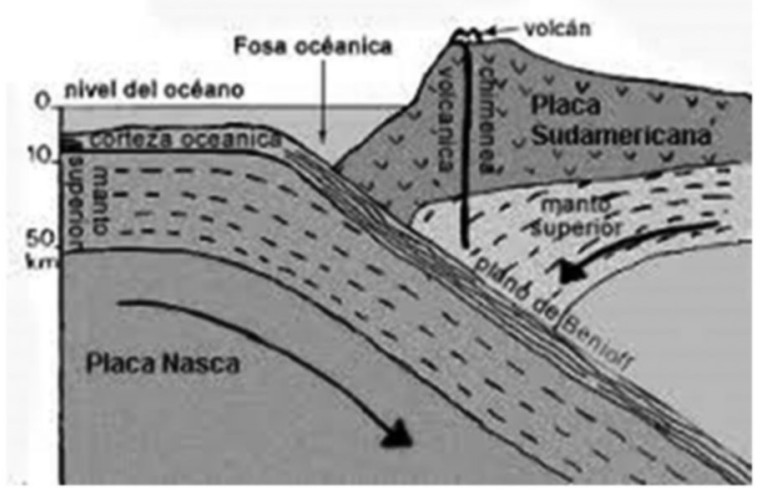

Fuente: Tomado http://www.predes.org.pe/predes/terremotos.htm Revisado el 10-I-2017

Es en esa zona donde se está acumulando tensión, por lo tanto, ha liberado energía en estos días, pero no sabemos cuánta energía es la acumulada; ¿Cómo se liberará? , ¿en varios sismos de magnitud sobre $7^{\circ}$ o en uno sólo igual o mayor a $8^{\circ}$ escala Richter? No lo sabemos. ¿Cuándo ocurrirá? La geofísica aún no tiene la capacidad de predecir, entonces surge la interrogante: ¿qué hay que hacer ante un potencial evento de gran magnitud?, por lo tanto, podemos hablar de incertidumbre y debemos trabajar y concientizar a la población, recordando que vivimos en uno de los países más sísmicos del mundo, pues si bien es importante saber cuándo podría ocurrir es de vital importancia intentar determinar otras variables como, por ejemplo, ¿cómo se producirá? ¿ ¿cuáles serán sus características? Y, lo más importante, ¿dónde?

Estas razones son suficientes para considerar que debemos continuar preparando a la población adulta, pero muy especialmente a la infantil, no sólo del norte de nuestro país, sino a nivel nacional (cultura sísmica), y también a la población de extranjeros inmigrantes que han llegado a nuestro país. Es nuestro deber saber cómo actuar ante un evento de esta naturaleza. 
El evento sísmico $6.5^{\circ}$ o $6.7^{\circ}$ que afectó en la última semana de marzo recientemente el norte chileno, si bien es cierto permitió observar que se evacuó con relativo éxito más de ciento veinte mil personas, algunas huyeron en automóviles (acción no considerada dentro del protocolo de evacuación), dadas las características de la morfología urbana de la ciudad de lquique (Figura 9), que corresponde a una extensa planicie Litoral se hace difícil la evacuación horizontal, especialmente para personas de determinada edad o con capacidades diferentes. La evacuación vertical, considerada dentro de los protocolos, no es tan eficiente o no ha sido internalizada, pensemos en un sismo grado 8 escala Richter, muchos de estos edificios pueden sufrir daños estructurales, pero mantenerse en pie; al ingresar o permitir el ingreso de personas desesperadas que huyen de un presunto tsunami, las estructuras con el peso de la multitud podrían colapsar; otra parte del protocolo dice que las personas deben intentar subirse a un techo o a un árbol, lo que es un ejercicio complejo y no fácil de realizar para personas mayores, niños o personas con capacidades diferentes.

Entonces surge la pregunta: ¿Qué hacemos entonces? Creo que en el caso de la ciudad de lquique u otras localizadas a escasos metros sobre el nivel del mar, debieran instalarse plazas o áreas verdes en altura que sirvan de protección a la población, concientizar sobre la evacuación vertical en las áreas bajo riesgo tsunámico de la ciudad como, por ejemplo, es el caso de la Zofri, Cavancha, y otras similares.

Como se sabe, la tierra está dividida en placas tectónicas que se desplazan a diversas velocidades y direcciones ( $\mathrm{cm}$.), en el caso chileno se genera un proceso de subducción, vale decir, choque de la Placa de Nazca oceánica, más densa, con la placa Sudamericana (más liviana). Estas placas tectónicas flotan en una capa de características semiplásticas denominada astenósfera, que permite que las placas de la corteza terrestre se muevan. Al chocar estas placas se genera tensión y acumulación de energía, la que cuando se libera genera una falla geológica de variada extensión y una subducción variable, la que va a depender de la energía liberada y de la magnitud del evento sísmico (Figura 6).

Cuando se analiza la distribución superficial de las placas que componen la litosfera terrestre (Figura 6), es posible observar cuáles son las zonas con mayor riesgo de estar afectadas por la actividad de éstas: todo el borde occidental de Sudamérica, el norte de la India, el norte del territorio australiano y el borde oriental asiático, por mencionar algunos.

En la imagen se puede apreciar la velocidad de desplazamiento promedio de las placas al año, en el caso próximo a los 7,5 cm., lo cual varía completamente cuando ocurren eventos sísmicos de gran magnitud como es el caso del terremoto del 27 de febrero del 2010, que afectó el centro sur de Chile, 
donde se estima que el desplazamiento entre placas alcanzó hasta los cinco metros en Concepción y unos 30 centímetros en Santiago (Zepeda, 2010). En su lugar el terremoto de abril de 2014 sólo generó desplazamientos de hasta $34 \mathrm{~cm}$. (Osorio, 2014), generando por ende cambios en la geomorfología y replanteo de la Red Geodésica Nacional.

Figura 6 Mapa de Placas tectónicas del mundo

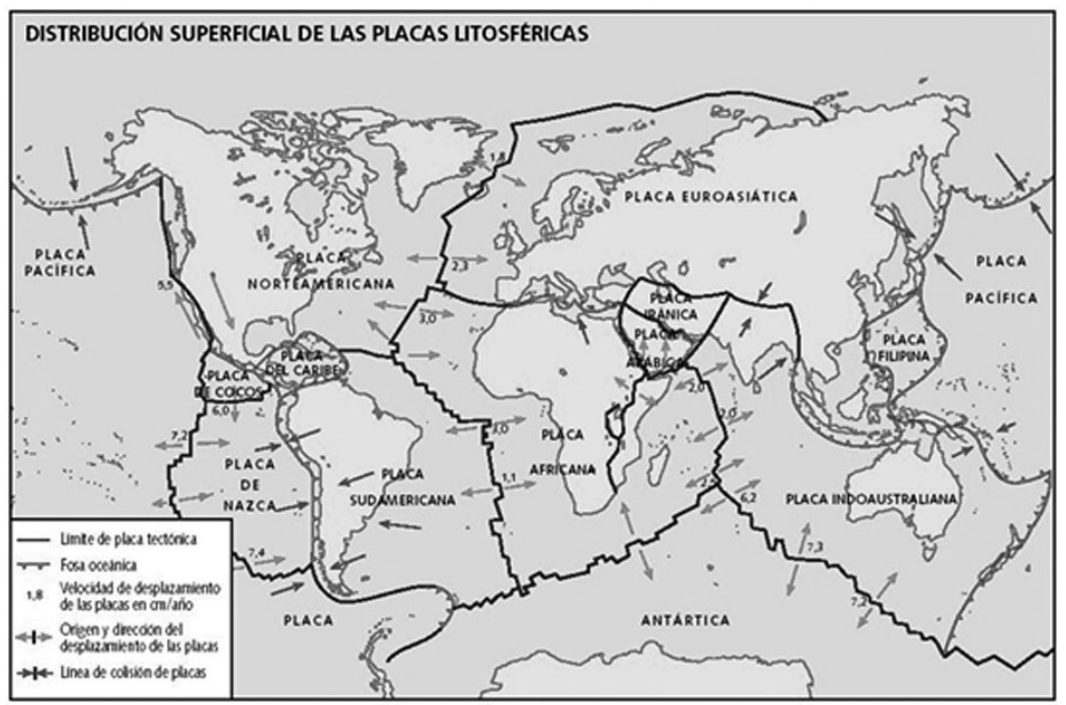

Fuente: Extraído desde http://2.bp.blogspot.com. Revisado el 15-III-2017.

En la zona norte de Chile y sur del Perú se han registrado más de mil sismos de variadas magnitudes, por lo que podríamos hablar de un enjambre sísmico. Lo que no sabemos es si efectivamente esta seguidilla de eventos sísmicos han liberado toda la energía o son un preludio de evento mayor. Sólo se sabe que hay energía acumulada que en algún momento tiene que liberarse, lo que no sabemos cuándo, con qué magnitud, por lo tanto, ante tal incertidumbre debemos estar lo mejor preparados, para poder evacuar con éxito el tercio de la población de lquique que está expuesta a riesgo tsunámico.

En la Figura 7, se observa que el modelo de riesgo tsunámico, utilizado en base al evento sísmico de 1968, indica que la zona de mayor impacto correspondería al sur de la ciudad, uno de los lugares afectados correspondería al hipódromo. El sector de la antigua Aduana y el sur del Morro de Arica también se verían afectados, y se debería prestar especial cuidado en las desembocaduras del río Lluta al sur (si existiesen asentamientos humanos, estos es muy probable que sean arrasados por los trenes de olas que entrarían por esta vía) y la quebrada de Azapa, que atraviesa perpendicularmente la ciudad, la cual es una zona más baja que enfrenta al mar y que canalizaría 
el agua por su interior hasta los sectores más adentrados de la ciudad, dependiendo del empuje de los trenes de olas.

Figura 7 Área de Inundación tsunámica, ciudad de Arica

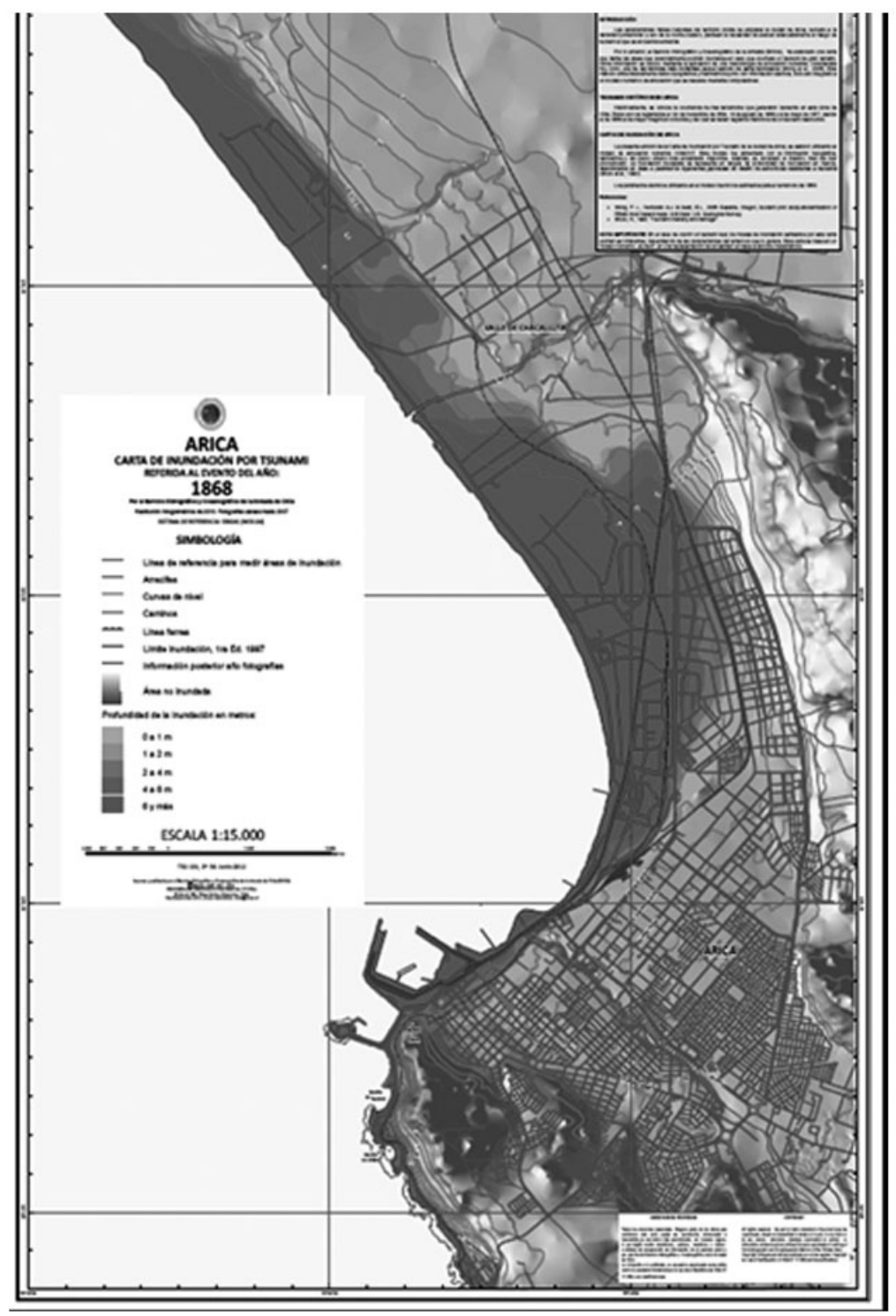

Fuente: Arica-SHOA. 
Figura 8 Área de Inundación tsunámica, ciudad de lquique

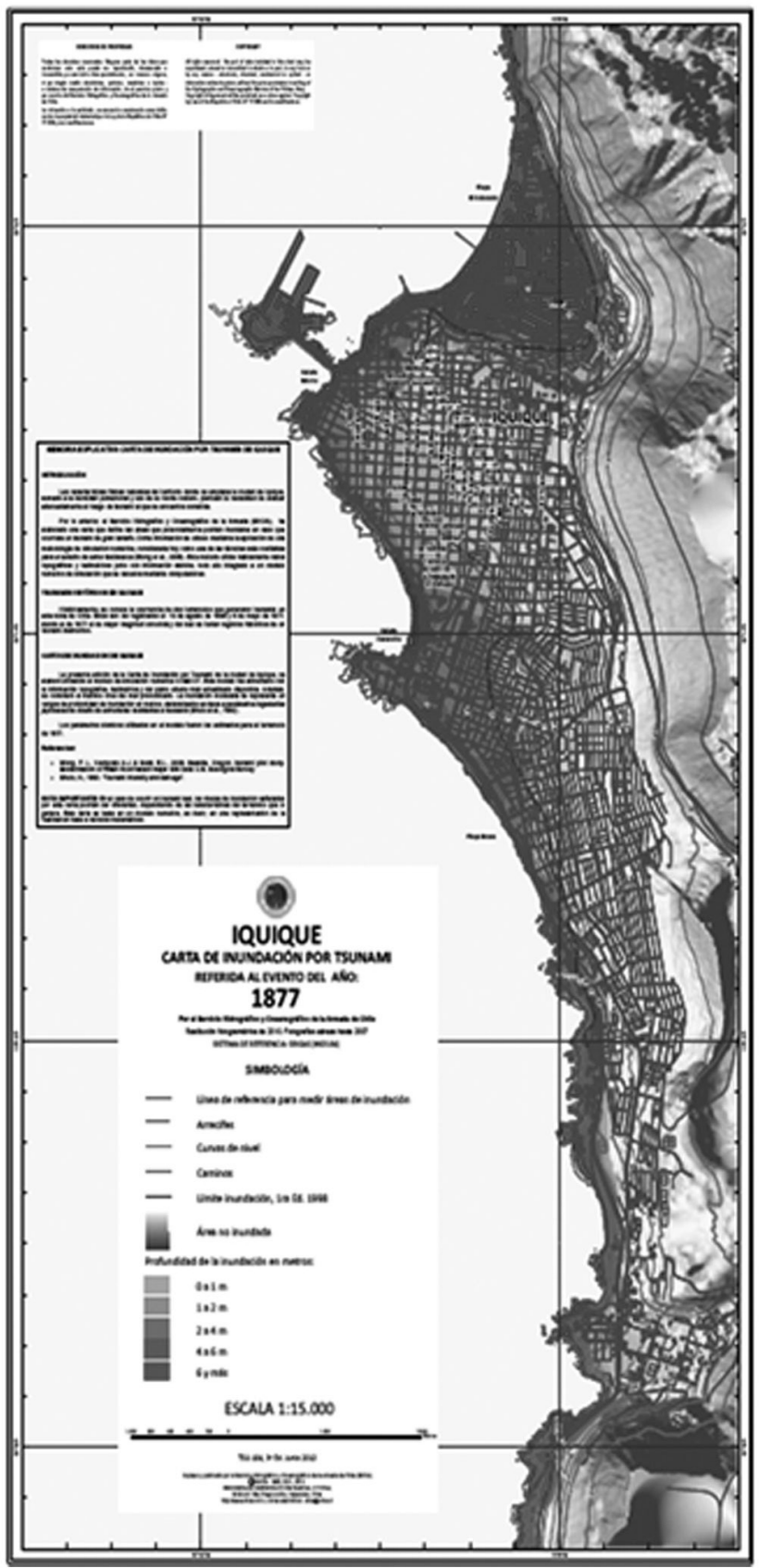

Fuente: Iquique-SHOA. 
Hay que tener presente que tanto los eventos tsunámicos, deslizamientos de laderas e incendios, son eventos colaterales de un sismo, especialmente de un sismo o movimiento de tierra de magnitud igual o superior a uno de 7.5 grados Richter, son los principales causantes de víctimas y heridos y no el sismo propiamente tal.

El megaterremoto del año 1960 que afectó el centro y sur de Chile, el más grande registrado instrumentalmente a nivel mundial, generó una falla geológica a lo largo de la zona de Subducción de más de mil km, con un desplazamiento en dirección de la zona de subducción (plano de Benioff), de unos 40 a 42 metros, alcanzando una magnitud de 9.5 grados Richter, el sismo más grande registrado en el mundo. A modo de comparación el terremoto del 27 de febrero del año 2010 que afectó el centro-sur chileno generó una falla geológica de unos 400 $\mathrm{km}$. de extensión y su desplazamiento fue entre 5 a 7 metros.

Estimo que ante un evento sísmico de elevada magnitud es conveniente sólo utilizar el concepto de magnitud, vale decir escala Richter o utilizar la escala Magnitud del Momento, vale decir entre grado y grado la energía liberada es 30 veces mayor, es conveniente no mezclar escalas científicas con escalas perceptivas como es el caso de la escala Modificada de Mercalli, lo que genera confusión a la población y en los medios de comunicación.

A modo de conclusión, siendo Chile uno de los países más sísmicos del mundo, desafortunadamente, a pesar de los esfuerzos científicos a nivel mundial, no es posible predecirlos; podemos medir el desplazamiento de las placas tectónicas (GPS), tener claridad en cuánto está subduccionando la placa de Nazca en relación con la continental, qué zonas de nuestro país están acumulando energía o tensión, pero no podemos determinar cuándo se producirá un evento sísmico y cuál será su magnitud. 
Figura 9 Daños provocados por el terremoto del 1 de abril de 2014, en la ciudad de Arica
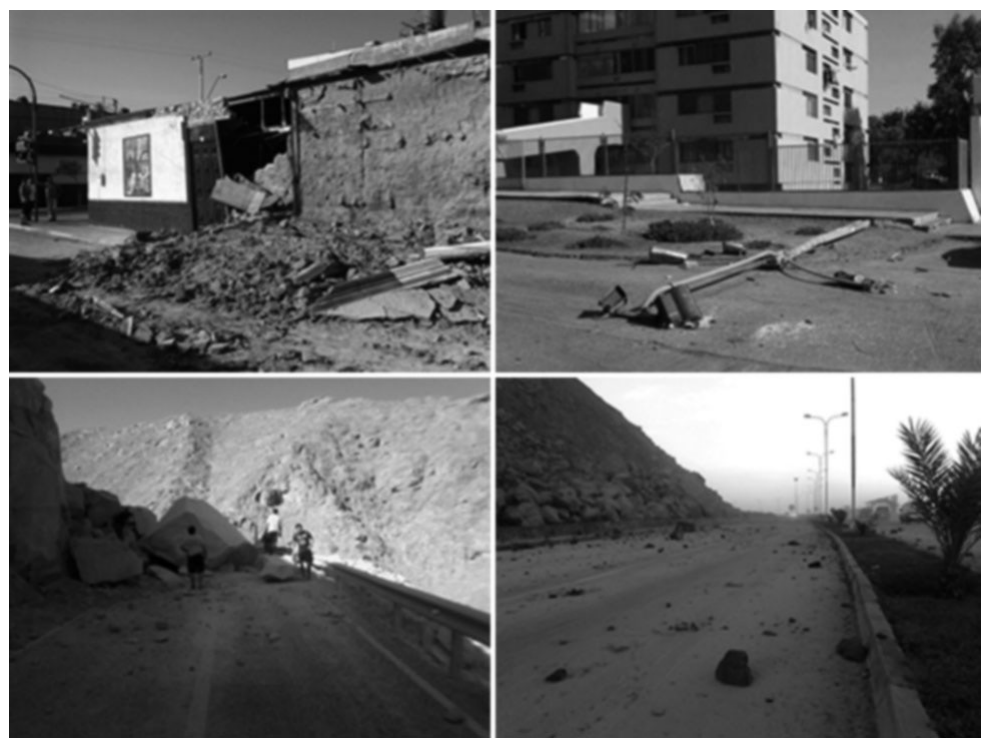

Fuente: Imágenes extraídas de http://www.soychile.cl. Revisado el 2-IV-2014.

Figura 10 Daños provocados por el terremoto del 1 de abril de 2014, en la ciudad de lquique
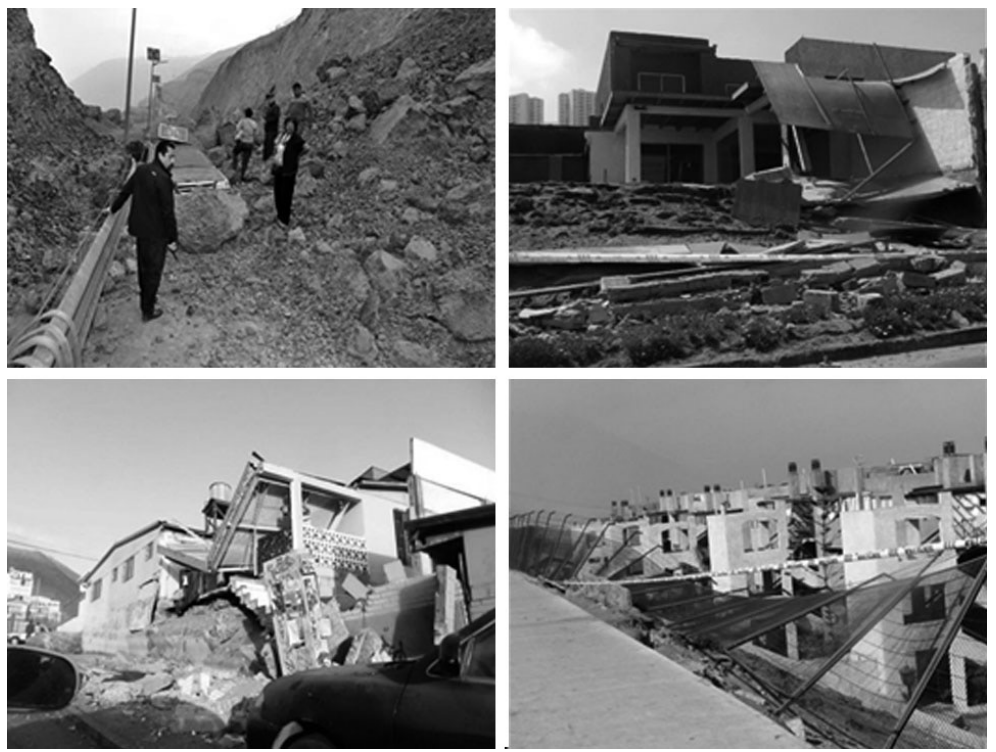

Fuente: Imágenes extraídas de http://www.publimetro.cl. Revisado el 2-IV-2014. 


\section{Referencias bibliográficas}

\section{Fuentes Primarias}

a) Documentos

Instituto Geológico Norteamericano (1971). Investiguemos la tierra. Proyecto ESCP-Ciencias de la tierra. Barcelona: Editorial Norma.

\section{b) Prensa periódica}

La Estrella de Arica, 25/08/2010, disponible en http://www.estrellaarica.cl, Revisado el 27-|||-2014.

La Nación, 08/04/2010, disponible en http://www.lanacion.cl/una-reflexion-sobreel-pasado-terremoto/noticias/2010-04-08/132217.html. Revisado el 28-II-2014.

\section{Fuentes Secundarias}

\section{a) Libros}

Gascón, M. (2005). Vientos, Terremotos, Tsunamis y otras catástrofes naturales. Buenos Aires: Editorial Biblos.

Infante, N. (2012). Monumento Natural El Morado, Andes centrales chilenos. Análisis del medio biofísico y propuestas para su gestión. Editorial Académica Española.

Nava, A. (2011). Terremotos. México: Fondo de Cultura Económica.

Strahler, A. (2005). Geografía Física. Estados Unidos: Editorial Omega.

\section{b) Recursos web}

Centro Sismológico Nacional. Universidad de Chile. http://www.sismologia.cl/

Infante, N. "Cómo entender los últimos movimientos sísmicos en Chile", en http://www.uiberoamericana.cl/noticias-verticales/como-entender-los-ultimosmovimientos-sismicos-en-chile-2

Osorio, V. Ministro de Bienes Nacionales (2014). En http://www.ahoranoticias. cl/pais/arica-y-parinacota/terremoto-genero-desplazamientos-de-tierra-de-hasta37-cm.html

Zepeda, R (2010). Desplazamiento de la tierra en Chile en el terremoto es impresionante. En http://www.cooperativa.cl/noticias/pais/sismos/catastrofe-en-chile/ experto-desplazamiento-de-la-tierra-en-chile-en-el-terremoto-es-impresionante/2010-04-20/074028.html 